[RAdiocarbon, Vol 22, No. 3, 1980, P 933-935]

\title{
EXPLORATORY ANALYSIS OF THE INTERNATIONAL RADIOCARBON CROSS-CALIBRATION DATA: CONSENSUS VALUES AND INTERLABORATORY ERROR \\ PRELIMINARY NOTE
}

\author{
LLOYD A CURRIE \\ National Bureau of Standards, Washington, DC 20234
}

and

HENRY A POLACH

The Australian National University, Canberra, ACT 2600, Australia

ABSTRACT. A preliminary review is given of the evaluation of the International $=508.1 \pm 2.0 \%$ R A NU Sucrose Data. Consensus values and standard errors are $\mathrm{D}^{14} \mathrm{C}$ $=508.1 \pm 2.0 \%$ (ANU Sucrose) and $\Delta=-2.5 \pm 1.5 \%$ (1850 Wood). Reporting format follows recommendations of Stuiver and Polach (1977).

\section{INTRODUCTION}

Data from the international cross-calibration exercise (Polach, 1979) have provided an important opportunity to assess the state of the art of high-precision natural radiocarbon measurement and to derive consensus values for two relatively pure and homogeneous materials relative to the international radiocarbon dating standard (NBS oxalic acid, SRM-4990B). Performance was good: some 15 laboratories returned results for the two ratios - ANU sucrose/modern standard (S/M) and $1850 \mathrm{wood} / \mathrm{modern}$ standard $(\mathrm{W} / \mathrm{M})$ - with a typical imprecision (standard deviation) of about $5 \%$; and the distributions of results were relatively narrow. The primary limitations encountered were (occasionally) incomplete laboratory data and variable reporting practices. A résumé of our analysis follows; a complete report incorporating results received since the Bern-Heidelberg conference is being prepared.

\section{Cross-calibration results}

A more detailed examination of the cross-calibration data, using assumption-resistant methods, has revealed that the agreement, while good, is not exceptional. Supplementing conventional data analysis techniques, the methods of Tukey (1977) and Youden (1960) were employed in order to expose and minimize the effects of systematic and non-Poisson random errors. Stem/leaf histograms (Tukey, 1977) showing the distributions of results are given in figure 1.

Some observations from our analysis of the radiocarbon data follow:

a) Imprecisions (standard deviations) quoted varied from about $2 \%$ to $8 \%$, with one laboratory reporting $28 \%$. Most but not all of the reported imprecisions represented counting statistics only. Weighted, iterative computations were employed to take into account non-counting errors and the variation in Poisson imprecision (Currie, 1972a).

b) Apparent blunders (large deviations from consensus values) occurred in a few cases; most severe were results for the estimate of the 
ratio $\mathrm{S} / \mathrm{M}$, where three observations differed by more than four times their stated imprecisions. Such large deviations were not obtained for the ratio $\mathrm{W} / \mathrm{M}$.

c) "Laboratory error", $\sigma_{\mathbf{x}}$, ie, a non-Poisson error component, was estimated from the data distributions for both ratios. Results were similar: for $\mathrm{S} / \mathrm{M}, \sigma_{\mathrm{x}}=3.5 \%$; for $\mathrm{W} / \mathrm{M}, \sigma_{\mathrm{x}}=1.8 \%$. Uncertainty intervals for $\sigma_{\mathrm{x}}$ were large due to the limited numbers of degrees of freedom, but only the latter $(\mathrm{W} / \mathrm{M})$ interval was consistent with $\sigma_{\mathrm{x}}=0$, ie, negligible non-Poisson error. These error estimates, which may reflect the accuracy limit for current counting techniques, are consistent with those given earlier by Pearson and others (3\%) (1977), Clark (6\%) (1975), and Currie $(5 \%$ ) (1972b).

d) Consensus ratios, following the use of exploratory techniques to identify blunders and taking into account "laboratory error" and varying Poisson imprecision, were $\mathrm{D}^{14} \mathrm{C}=508.1 \pm 2.0 \%$ (sucrose) and $\Delta=-2.5 \pm 1.5 \%$ (1850 wood, age-corrected for decay to 1950). (Uncertainties represent one standard error, and both $\mathrm{S}$ and $\mathrm{W}$ are normalized to $\delta^{13} \mathrm{C}_{\mathrm{PDB}}=-25 \%$.)

\section{CROSS-CALIBRATION HISTOGRAMS}

(corrected ${ }^{14} \mathrm{C}$ deviations, in $\% 0$ )

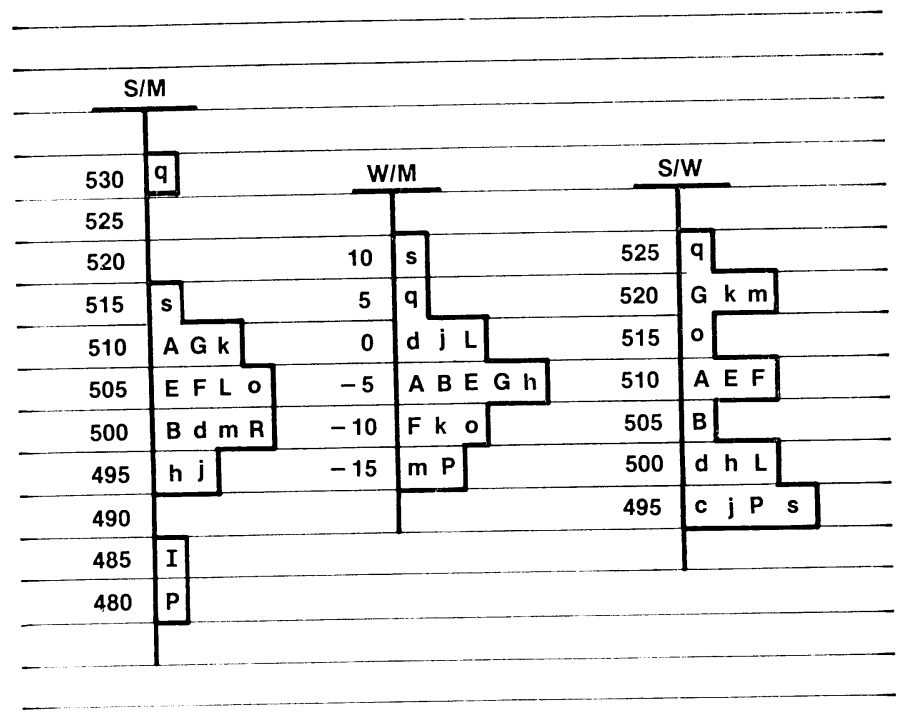

- S, M, W = Sucrose, Modern Standard, Wood

- $\sigma_{i}=2 \% 00-4 \%$ (Cap.); 5\%00-8\% (Lower Case)

Fig 1. Histogram of the radiocarbon ratios for ANU sucrose (S), 1850 wood (W) and the modern standard (M; $0.95 \times$ NBS oxalic acid). Numerical scales are expressed as deviations (in parts per thousand) from unity for each of the three ratios; and laboratories are coded alphabetically. 
Evaluation of the reported data for $\delta^{13} \mathrm{C}_{\mathrm{PDB}}$ indicated an overall imprecision (standard deviation) of about $0.35 \%$. Median values and standard errors for the three materials were: $-10.8 \pm 0.1 \%$ (S),$-19.1 \pm$ $0.1 \%$ o $(\mathrm{M}),-22.5 \pm 0.1 \%(\mathrm{~W})$. These results were derived from 18 observations (no outliers), 13 observations (3 outliers), and 15 observations (4 outliers), respectively. Discordant results for the oxalic acid and 1850 wood differed by up to $2 \%$ to $3 \%$ from the respective medians; they appear to be related to problems with isotopic fractionation in the use of these materials.

Further results of the evaluation, including $\delta^{13} \mathrm{C}$ distributions and the search for measurement method-, sample nature-, and isotope fractionation-related effects will be presented in the full report. The general conclusion, however, is that none of these factors limit the quality of results from experienced investigators. Reporting practice variance, however, places a significant and needless limitation on high-accuracy data. Among the problems noted were: lack of information on noncounting error, different age-correction and ${ }^{13} \mathrm{C}$ calibration practices, and the use of 0.949 versus 0.950 to convert measurements of oxalic acid to the "modern standard."

\section{REFERENCE}

Clark, R M, 1975, A calibration curve for radiocarbon dates: Antiquity, v 49, p 251-266. Currie, L A, 1972a, The limit of precision in nuclear and analytical chemistry: Nuclear Instruments Methods, v 100, p 387-395.

1972b, The evaluation of radiocarbon measurements and inherent statistical limitations in age resolution, in Rafter, $\mathbf{T} \mathbf{A}$ and Grant-Taylor, $\mathbf{T}$, eds, Internatl conf on radiocarbon dating, 8th, Proc: Wellington, Royal Soc New Zealand,
p 598-611.

Pearson, G W, Pilcher, J R, Baillie, M G L, and Hillam, J, 1977, Absolute radiocarbon dating using a low altitude European tree-ring calibration: Nature, v 270, p 25-28.

Polach, H A, 1979, Correlation of ${ }^{14} \mathrm{C}$ activity of NBS oxalic acid with Arizona 1850 wood and ANU sucrose standards, in Berger, Rainer and Suess, H E, eds, Radiocarbon Dating, Internatl radiocarbon conf, 9th, Proc: Berkeley/Los Angeles, Univ California Press, p 115-124.

Stuiver, Minze and Polach H A, 1977, Discussion: Reporting of ${ }^{14} \mathrm{C}$ data: Radiocarbon, v 19, p 355-363.

Tukey, J W, 1977, Exploratory data analysis: Reading, Massachusetts, Addison-Wesley. Youden, W J, 1960, The sample, the procedure, and the laboratory: Anal Chemistry, v 32 , no. 13 , p $23 \mathrm{~A}-37 \mathrm{~A}$ 